\title{
A Phase I clinical study of cisplatin-incorporated polymeric micelles (NC-6004) in patients with solid tumours
}

\section{R Plummer', RH Wilson', H Calvert',7, AV Boddy', M Griffin', J Sludden', MJ Tilby', M Eatock', DG Pearson ${ }^{3}$, CJ Ottley ${ }^{3}$, Y Matsumura ${ }^{4}, K_{\text {Kataoka }}{ }^{5}$ and T Nishiya ${ }^{*, 6}$}

'Northem Institute for Cancer Research, Paul O'Gorman Building, Framlington Place, Newcastle upon Tyne NE2 4AD, UK; ' Centre for Cancer Research and Cell Biology, Queen's University Belfast, Lisburn Road, Belfast BT9 7AB, Northern Ireland, UK; ${ }^{3}$ Department of Earth Sciences, University of Durham, Science Labs, Durham DHI 3LE, UK; ${ }^{4}$ Investigative Treatment Division, Research Center for Innovative Oncology, National Cancer Center Hospital East, 6-5-I Kashiwanoha, Kashiwa, Chiba 277-8577, Japan; ${ }^{5}$ Department of Materials Engineering, Graduate School of Engineering, and Center for Disease Biology and Integrative Medicine, Graduate School of Medicine, The University of Tokyo, 7-3-I Hongo, Bunkyo-ku, Tokyo II 3-8656, Japan;

${ }^{6}$ Division of Clinical Study, NanoCarrier Co. Ltd, Yaesu Yamagata Building, 3-2-2 Nihonbashi, Chuo-ku, Tokyo 103-0027, Japan

BACKGROUND: On the basis of preclinical studies of NC-6004, a cisplatin-incorporated micellar formulation, we hypothesised that NC-6004 could show lower toxicity than cisplatin and show greater anti-tumour activity in phase I study.

METHODS: A total of 17 patients were recruited in a range of advanced solid tumour types. NC-6004 was administered intravenously (i.v.) every 3 weeks. The dose escalation started at $10 \mathrm{mg} \mathrm{m}^{-2}$ and was increased up to $120 \mathrm{mg} \mathrm{m}^{-2}$ according to the accelerated titration method and modified Fibonacci method.

RESULTS: One dose-limiting toxicity (DLT) occurred in a patient who was given $90 \mathrm{mg} \mathrm{m}^{-2}$ of NC-6004, otherwise any significant cisplatin-related toxicity was not observed or generally mild toxicity was observed. Despite the implementation of post-hydration and pre-medication regimen, renal impairment and hypersensitivity reactions still developed at $120 \mathrm{mg} \mathrm{m}^{-2}$, which led to the conclusion that the maximum tolerated dose was $120 \mathrm{mg} \mathrm{m}^{-2}$, and the recommended dose was $90 \mathrm{mg} \mathrm{m}^{-2}$, although DLT was not defined as per protocol. Stable disease was observed in seven patients. The maximum concentration and area under the concentration-time curve of ultrafilterable platinum at $120 \mathrm{mg} \mathrm{m}^{-2} \mathrm{NC}-6004$ were 34-fold smaller and 8.5-fold larger, respectively, than those for cisplatin.

CONCLUSION: The delayed and sustained release of cisplatin after i.v. administration contributes to the low toxicity of NC-6004.

British Journal of Cancer (20II) I 04, 593-598. doi:I0.1038/bjc.20II.6 www.bjcancer.com

Published online I February 20 I

(C) 201। Cancer Research UK

Keywords: cisplatin; DDS; EPR effect; NC-6004; phase I study; polymer micelle

Cisplatin, cis-diamminedichloroplatinum (II), is a platinum (Pt)based chemotherapy drug used to treat various types of cancers. Clinical use of cisplatin is, however, associated with irreversible renal toxicity, which necessitates the use of pre- and posthydration regimens, and excludes its use in patients with less than normal renal function (Pinzani et al, 1994). Cisplatin therapy also causes neurotoxicity, gastrointestinal toxicity (nausea and vomiting), haematological toxicity, and irreversible ototoxicity (Hartmann and Lipp, 2003). Furthermore, its anti-tumour efficacy continues to be limited by either intrinsic or acquired resistance (Kartalou and Essigmann, 2001). To overcome these cisplatinrelated disadvantages, various types of Pt analogues, including carboplatin, oxaliplatin, satraplatin, and picoplatin have been developed (Kelland and Sharp, 1999; Judson and Kelland, 2000; Sharp et al, 2002). Another potential method for improving the

\footnotetext{
*Correspondence: Dr T Nishiya;

E-mail address: nishiya@nanocarrier.co.jp

${ }^{7}$ Current address: UCL Cancer Institute, Paul O'Gorman Building, 72 Huntley Street, London WCIE 6BT, UK.

Received 10 November 20 I0; revised 21 December 2010; accepted 29 December 20 I0; published online I February 20 I |
}

therapeutic indices of cisplatin is the incorporation of cisplatin into polymeric micelles of varying size in the range of $20-100 \mathrm{~nm}$ composed of polyethylene glycol (PEG)-poly (amino acid) block co-polymers, in which PEG constitutes the hydrophilic outer shell of the micelle and cisplatin is incorporated into hydrophobic inner core of the micelle (Yokoyama et al, 1996; Nishiyama et al, 1999, 2001b, 2003; Nishiyama and Kataoka, 2001a).

Preclinical studies carried out on NC-6004, cisplatin-incorporated polymeric micelles composed of PEG-poly (glutamic acid) block co-polymers via polymer-metal complex formation (Figures 1 and 2), have indicated that it is preferentially distributed to tumours by enhanced permeability and retention effect (Matsumura and Maeda, 1986; Maeda and Matsumura, 1989; Maeda et al, 2000; Maeda, 2001), and demonstrates significantly lower toxicity than cisplatin and greater anti-tumour activity (Uchino et al, 2005). On the basis of these results, a phase I clinical trial of NC-6004 in patients with advanced solid tumours has been carried out. The objectives of the study were to determine the maximumtolerated dose (MTD), the recommended dose (RD) for the phase II, the dose-limiting toxicities (DLTs), the safety and tolerability profile, and to explore evidence of anti-tumour activity, and the pharmacokinetics of NC-6004. 


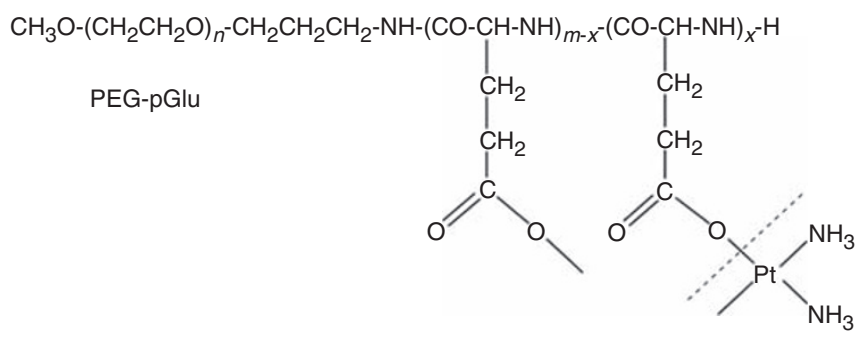

Cisplatin residue

Figure I Structure of cisplatin-PEG-poly(glutamic acid) block co-polymer conjugate. PEG-pGlu, PEG-poly(glutamic acid); n, approximately 268; m, approximately 40; $x$, approximately 24 .

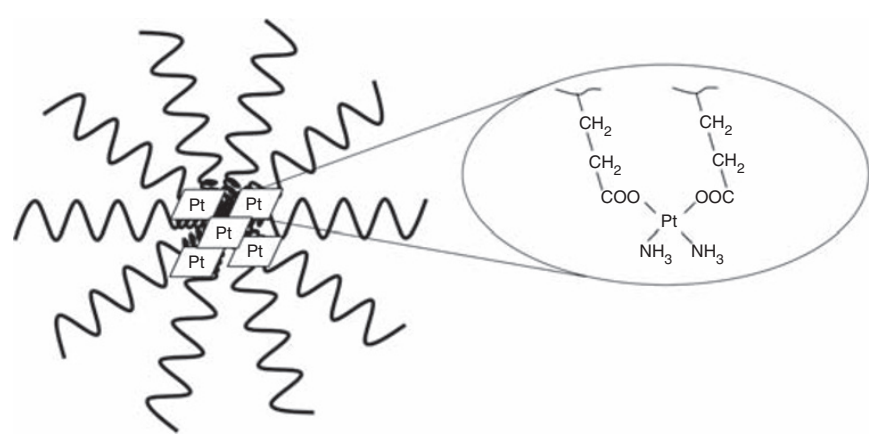

Figure 2 Structure of cisplatin-incorporated polymeric micelle, NC-6004. Core part, cisplatin residue bound to poly-L-glutamic acid. Exterior part, PEG.

\section{PATIENTS AND METHODS}

\section{Ethics}

The trial was an open-label, dose-escalating, phase I study conducted at two sites in the United Kingdom; Newcastle General Hospital and Belfast City Hospital. All procedures were reviewed by Independent Ethics Committees, and were in accordance with the protocol, the Helsinki Declaration (October 2000, and clarified 2002 and 2004), the Note for Guidance on Good Clinical Practice (CPMP/ICH/135/95) approved in July 1996, and the applicable regulatory requirements.

\section{Administration of therapeutic agent}

NC-6004 (NanoCarrier Co., Ltd Chiba, Japan) was a sterile solution containing the equivalent of $2.5 \mathrm{mg} \mathrm{ml}^{-1}$ cisplatin and could be diluted in $5 \%$ dextrose before administration.

Dosing was performed by intravenous (i.v.) infusion of $500 \mathrm{ml}$ over $60 \mathrm{~min}$, once every 3 weeks. Following the observation of renal toxicities, hydration using 1000 to $1500 \mathrm{ml}$ of fluid, immediately after NC-6004 infusion, was implemented for the rest of the study. Later in the study, after the occurrence of four events of hypersensitivity reactions, the following prophylactic treatment was implemented at each cycle for all patients; $30 \mathrm{~min}$ before infusion - dexamethasone $20 \mathrm{mg}$ i.v., chlorphenamine $10 \mathrm{mg}$ i.v., and ranitidine $50 \mathrm{mg}$ i.v. Oral dexamethasone $4 \mathrm{mg}$ (twice a day), ranitidine $150 \mathrm{mg}$ (twice a day), and chlorphenamine $4 \mathrm{mg}$ (three times a day) could also be given if necessary on a per-patient individualised basis for $48 \mathrm{~h}$ after infusion.

\section{Patients' eligibility and dose escalation}

Patients with histologically confirmed advanced solid tumours, for which no standard therapy exists or has failed therapy, were eligible for enrolment in this study, provided that the following criteria were met: Eastern Cooperative Oncology Group performance
Table I Dose modification for changes in estimated creatinine clearance or ${ }^{51} \mathrm{Cr}$-EDTA clearance

\begin{tabular}{|c|c|c|c|}
\hline $\begin{array}{l}\text { Estimated creatinine } \\
\text { clearance/GFR }\end{array}$ & $\begin{array}{l}\text { NC-6004 } \\
\text { dose }\end{array}$ & $\begin{array}{c}{ }^{51} \text { Cr-EDTA } \\
\text { clearance } \\
\left(\text { in } \mathrm{ml} \mathrm{min}^{-1} \text { ) }\right.\end{array}$ & $\begin{array}{l}\text { NC-6004 } \\
\text { dose }\end{array}$ \\
\hline $\begin{array}{l}>60 \mathrm{ml} \mathrm{min} \mathrm{m}^{-1} \\
50-60 \mathrm{ml} \mathrm{min}^{-1} \\
<50 \mathrm{ml} \mathrm{min}^{-1} \text { or } \\
\text { any drop from } \\
\text { baseline by }>10 \% \\
\text { calculated GFR }\end{array}$ & $\begin{array}{c}100 \% \text { of dose } \\
\text { 80\% of dose } \\
{ }^{51} \mathrm{Cr} \text {-EDTA clearance } \\
\text { measurement }\end{array}$ & $\begin{array}{c}>60 \\
40-60 \\
<40\end{array}$ & $\begin{array}{c}100 \% \text { of dose } \\
50 \% \text { of dose } \\
\text { Discontinue }\end{array}$ \\
\hline
\end{tabular}

Abbreviations: ${ }^{51} \mathrm{Cr}$-EDTA clearance $=$ chromium-5I-ethylenediaminetetraacetic acid clearance; GFR = glomerular filtration rate.

status of $\leqslant 2$; age of $\geqslant 18$ years; life expectancy of at least 12 weeks; a normal haematological profile, renal function, hepatic function, and serum calcium level, no more than one previous course of $\mathrm{Pt}$ therapy, with maximum cumulative doses of $480 \mathrm{mg} \mathrm{m}^{-2}$ of cisplatin, $1040 \mathrm{mg} \mathrm{m}^{-2}$ of oxaliplatin, or $42 \mathrm{mg} \mathrm{ml}^{-1}$ $\min ^{-1}$ ( $\min =$ minutes) cumulative area under the concentrationtime curve (AUC) of carboplatin, and no chemotherapy, no radiotherapy (except palliative radiation delivered to $<20 \%$ of bone marrow), no immunotherapy, or no corticosteroids (greater than $10 \mathrm{mg}$ per day of prednisone or equivalent) within 4 weeks before entering the study or patients who have not recovered from adverse events because of agents administered more than 4 weeks earlier. Patients who had severe hypersensitivity to Pt compounds, ototoxicity assessed by audiometry (except senile hearing loss at high frequency) or other neurotoxicity $\geqslant$ grade 2 were ineligible for enrolment in the study. Patients were excluded if they were pregnant or lactating.

The dose of NC-6004 is, hereafter, always expressed as cisplatin equivalent $\mathrm{mg} \mathrm{m}^{-2}$ of body surface area per injection. The starting dose of NC-6004 was $10 \mathrm{mg} \mathrm{m}^{-2}$, one-tenth of the lethal dose in $10 \%$ in rat or one-third of the toxic dose low in dog. In stage 1 , (accelerated titration method), each dose was escalated at twice the previous dose level until drug-related toxicity $\geqslant$ grade 2 was seen in cycle 1 . Once the first drug-related toxicity $\geqslant$ grade 2 in cycle 1 was seen, a minimum cohort of three patients was recruited, and each dose was defined as $150 \%$ of the previous one in stage 2 (modified Fibonacci method) until MTD was reached. The dose was modified according to the estimated creatinine clearance $(\mathrm{Cl}) /$ GFR measured before each administration of NC-6004 as detailed in Table 1. Intra-patient dose escalation was not permitted.

Toxicity was graded by the Common Terminology Criteria for Adverse Events version 3.0. MTD was defined as the dose at which one-third of patients experience DLT, and RD was the highest dose, which gave rise to no more than one DLT out of a cohort of six patients. DLTs were defined as grade 4 neutropenia associated with fever $\left(\geqslant 38.5^{\circ} \mathrm{C}\right)$ or diarrhoea $\geqslant$ grade 2 , grade 4 neutropenia lasting $\geqslant 5$ days without fever, grade 4 thrombocytopenia for $\geqslant 5$ days, grade 3 or higher non-haematological toxicity (except liver transaminase elevation, or nausea or vomiting treatable by antiemetic), and treatment delay $>2$ weeks before start of next cycle of treatment because of unresolved toxicity.

\section{Pretreatment assessment and follow-up studies}

Assessment of medical history was completed during the 21 days before the start of NC-6004 dosing. Safety was monitored throughout the trial until the end of trial visit. In the treatment phase, physical assessment, routine laboratory analysis, estimated creatinine $\mathrm{Cl}$, and concurrent illness/therapy were reviewed on day 1 of cycle 1 , then every week until week 7 and then every 3 weeks thereafter, and at withdrawal from the trial. Adverse events were reviewed during the first 4 days of cycle 1, then every week from 
weeks 2 to 7 and then every 3 weeks from week 7 onwards, and at withdrawal. The CT/MRI scans of all target and non-target lesions were performed every 6 weeks and at withdrawal, and tumour markers, if applicable, were assessed every 3 weeks. The Response Evaluation Criteria in Solid Tumour (RECIST) was used to define lesions and the criteria for objective tumour response. For pharmacokinetic analysis, blood samples were taken at $0,2,4$ and $8 \mathrm{~h}$ after administration on days $1,2,3,4,8,15$, and 22 and before cycle 2 .

\section{Pharmacokinetic analysis}

Blood samples were centrifuged and separated plasma was processed to produce three different forms of sample: total plasma, gel filtrate and ultrafiltrate. Plasma $(1 \mathrm{ml})$ was stored for totalplasma Pt analysis. Plasma $(1 \mathrm{ml})$ was centrifuged with a molecular weight cutoff of $200000 \mathrm{Da}$, and the eluant was analysed for micellar Pt. Finally, a further $1 \mathrm{ml}$ of plasma was centrifuged with a molecular weight cutoff of $30000 \mathrm{Da}$ to give an ultrafiltrate for the determination of low-molecular weight Pt species, including cisplatin. Concentration of total plasma Pt and micellar Pt (gel filtrate) were measured using atomic absorption spectrometry on Analyst 600 (Perkin-Elmer, Waltham, MA, USA) against standards prepared in plasma. Ultrafiltrate samples were analysed by inductively coupled plasma mass spectrometry on Element 2 (Thermo Scientific Inc., Waltham, MA, USA) against centrifuged Pt standards at Durham University. Pharmacokinetic analysis was performed using WinNonlin version 1.3 (Pharsight Corporation, Mountain View, CA, USA) to calculate the maximum concentration $\left(C_{\max }\right)$, the time to the maximum concentration $\left(T_{\max }\right)$, elimination half-life $\left(t_{1 / 2}\right)$, and the AUC from zero to infinity $\left(\mathrm{AUC}_{\mathrm{inf}}\right)$ for all $\mathrm{Pt}$ species. Clearance $(\mathrm{Cl})$ and volume of distribution $\left(V_{\mathrm{z}}\right)$ were calculated for total plasma Pt.

\section{RESULTS}

\section{Patient characteristics}

The first patient was dosed on 15 May 2006 and the last study exit visit occurred on 6 February 2008. In total, 17 patients were enrolled and each received at least one dose of NC-6004, representing the intention-to-treat population. Demographic characteristics of patients are summarised in Table 2. All recruited patients were Caucasian, with a median height of $170.0 \mathrm{~cm}$ and a median weight of $73.0 \mathrm{~kg}$. Cancer history of patients is summarised in Table 3. The range of tumour types was large, with no specific tumour type represented more across the different groups. Tumour stage was similar between the dosing cohorts.

\section{Dosing and toxicity}

The process for dose escalation is shown in Table 3. In total, 41 doses were administered to 17 patients. The maximum number of treatments was four cycles in three patients, and the mean number of administrations per patient was 2.4 cycles. Dose escalation started at $10 \mathrm{mg} \mathrm{m}^{-2}$ and was increased up to $40 \mathrm{mg} \mathrm{m}^{-2}$ following the accelerated titration method. Owing to grade 2 renal toxicity in cycle 1 of a patient at $40 \mathrm{mg} \mathrm{m}^{-2}$, reported as a serious adverse event (SAE), the study entered stage 2 with a dose escalation up to $120 \mathrm{mg} \mathrm{m}^{-2}$ according to modified Fibonacci method.

Infusion-related adverse events are summarised in Table 4. NC-6004 injection was well tolerated in terms of haematological toxicities. Thus, one episode of grade 3 thrombocytopenia at $10 \mathrm{mg} \mathrm{m}^{-2}$ and grade 1 thrombocytopenia at $90 \mathrm{mg} \mathrm{m}^{-2}$ only were observed (not DLTs). For non-haematological toxicity, the most frequent related adverse events were fatigue (52.9\%), anorexia and nausea $(47.1 \%)$, vomiting $(41.2 \%)$, and hypersensitivity reaction and renal impairment $(35.3 \%)$. Significant cisplatin-related ototoxicity and neurotoxicity were not observed at any dose level.
Table 2 Patient characteristics

\begin{tabular}{|c|c|c|c|c|c|c|c|}
\hline \multirow[b]{3}{*}{$n$} & \multicolumn{7}{|c|}{ NC-6004 dose level (in $\mathrm{mg} \mathrm{m}^{-2}$ ) } \\
\hline & 10 & 20 & 40 & 60 & 90 & 120 & Total \\
\hline & I & I & 3 & 3 & 6 & 3 & 17 \\
\hline \multicolumn{8}{|l|}{ Age (years) } \\
\hline Range & 55 & 63 & $45-65$ & $45-56$ & $48-80$ & $40-71$ & $40-80$ \\
\hline \multicolumn{8}{|l|}{ Sex } \\
\hline Male & । & 0 & 2 & 2 & 4 & I & 10 \\
\hline Female & 0 & I & I & I & 2 & 2 & 7 \\
\hline \multicolumn{8}{|l|}{ ECOG PS ${ }^{\mathrm{a}}$} \\
\hline 0 & 1 & 0 & 2 & 1 & 4 & 2 & 10 \\
\hline I & 0 & 0 & 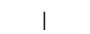 & 0 & I & I & 3 \\
\hline 2 & 0 & I & 0 & I & 1 & 0 & 3 \\
\hline \multicolumn{8}{|l|}{ Previous treatment } \\
\hline Chemotherapy & । & । & 3 & 3 & 5 & 2 & 15 \\
\hline Surgery & 0 & 0 & 3 & 3 & 3 & 3 & 12 \\
\hline Radiotherapy & 0 & I & I & 2 & 0 & 3 & 7 \\
\hline $\begin{array}{l}\text { Other therapies for } \\
\text { cancer (targeted therapy, } \\
\text { immunotherapy, or } \\
\text { epigenetic therapy) }\end{array}$ & 0 & 0 & 0 & 2 & । & 2 & 5 \\
\hline
\end{tabular}

Abbreviation: ECOG PS=Eastern Cooperative Oncology Group performance status. ${ }^{\text {a }}$ For one patient at $60 \mathrm{mg} \mathrm{m}^{-2}$, ECOG PS was not assessed at screening, but was assessed at day I before infusion.

One out of six patients at $90 \mathrm{mg} \mathrm{m}^{-2}$ experienced grade 3 fatigue in cycle 1 (DLT). One out of three patients at $60 \mathrm{mg} \mathrm{m}^{-2}$ had grade 3 vomiting in cycle 1 , and one patient in each 60,90 , and $120 \mathrm{mg} \mathrm{m}^{-2}$ developed grade 3 hypersensitivity reaction (not DLTs). The clinical signs and symptoms of hypersensitivity reactions to NC-6004 were urticarial rash, dizziness, sweating, cough, dyspnoea, hypotension, tingling, swelling of tongue, lip, and pharynx, tightness in chest, and burning sensation, some of which are typical reactions for $\mathrm{Pt}$, and they always developed after a minimum of two cycles of NC-6004. Other infusion-related toxicities were grade 2 or lower. Despite the implementation of post hydration (from $40 \mathrm{mg} \mathrm{m}^{-2}$ onwards) and hypersensitivity prophylaxis (from $90 \mathrm{mg} \mathrm{m}^{-2}$ onwards), grade 2 renal toxicity accompanied by a reduction in dose and/or delay in dose for 1 week was still observed at 90 and $120 \mathrm{mg} \mathrm{m}^{-2}$, and grade 2 and 3 hypersensitivity reactions (SAEs) also developed at $120 \mathrm{mg} \mathrm{m}^{-2}$. Following these events, it was considered that adding further patients or increasing the dose level would not be reasonable, and the study was discontinued at dosage level of $120 \mathrm{mg} \mathrm{m}^{-2}$. As the effect on renal function at $90 \mathrm{mg} \mathrm{m}^{-2}$ dosage was less marked than that observed at $120 \mathrm{mg} \mathrm{m}^{-2}$, the $120 \mathrm{mg} \mathrm{m}^{-2}$ dosage was considered to be the MTD, and the RD of NC-6004 as monotherapy for further studies was therefore estimated to be $90 \mathrm{mg} \mathrm{m}^{-2}$, although renal toxicity and hypersensitivity reactions were not defined as potential DLT per protocol.

\section{Therapeutic response}

Best overall response calculated by RECIST is shown in Table 3. No patient was assessed as complete response or partial response. Seven patients $(41.2 \%)$ were evaluated as having had a stable disease (SD) for longer than 4 weeks at the time of the study completion, even though six of these had advanced Stage IV solid tumours. It should be noted that only two out of eight patients (25\%) at the dose levels from 10 to $60 \mathrm{mg} \mathrm{m}^{-2}$ had a best response of SD, however the SD ratios at 90 and $120 \mathrm{mg} \mathrm{m}^{-2}$ were 50 and $67 \%$ respectively, suggesting that the efficacy of NC-6004 is more pronounced at higher dose levels. Overall, 14 patients (82.4\%) died or experienced tumour progression, and median progression-free survival time was 49 days. 
Table 3 Process for dose escalation

\begin{tabular}{|c|c|c|c|c|c|c|}
\hline $\begin{array}{l}\text { Dose } \\
\left(\mathrm{mg} \mathrm{m}^{-2}\right)\end{array}$ & $\begin{array}{l}\text { Patient } \\
\text { no. }\end{array}$ & $\begin{array}{l}\text { Primary } \\
\text { tumour (stage) }\end{array}$ & $\begin{array}{l}\text { Cycles } \\
\text { received }\end{array}$ & $\begin{array}{l}\text { No. of } \\
\text { DLT }\end{array}$ & Events & $\begin{array}{l}\text { Best overa } \\
\text { response }\end{array}$ \\
\hline \multicolumn{7}{|l|}{ Stage 1} \\
\hline 10 & 101 & Lung (IV) & 3 & 0 & Hypersensitivity reaction at cycle 3 (previous cisplatin therapy) & SD \\
\hline 20 & 102 & Lung (IV) & 2 & 0 & & PD \\
\hline \multirow[t]{3}{*}{40} & 103 & Colon (IV) & I & 0 & $\begin{array}{l}\text { Grade } 2 \text { reduced renal function at cycle I (SAE). Cohort was } \\
\text { expanded with two more patients. }\end{array}$ & PD \\
\hline & 204 & Hepatic cell (IV) & 4 & 0 & & SD \\
\hline & 105 & Colon (IV) & 2 & 0 & $\begin{array}{l}\text { Grade I reduced renal function at cycle I. Hydration was implemented } \\
\text { for the rest of study. }\end{array}$ & PD \\
\hline \multicolumn{7}{|l|}{ Stage 2} \\
\hline \multirow[t]{3}{*}{60} & 106 & Mesothelioma (IIIA) & 2 & 0 & Hypersensitivity reaction at cycle 2 (previous carboplatin therapy). & PD \\
\hline & 207 & Colon (IV) & 2 & 0 & Hypersensitivity reaction at cycle 2 (previous oxaliplatin therapy). & PD \\
\hline & 108 & Oesophagus (IV) & 2 & 0 & & NE \\
\hline \multirow[t]{6}{*}{90} & 209 & Pancreas (IIA) & 4 & 0 & $\begin{array}{l}\text { Hypersensitivity reaction at cycle } 4 \text { (Pt-naïve). Prophylactic treatment } \\
\text { was implemented for the rest of study. }\end{array}$ & SD \\
\hline & 110 & Oesophagus (IV) & 2 & 0 & Grade 2 reduced renal function at cycle 1. & PD \\
\hline & 112 & GIST (IV) & 2 & 0 & $\begin{array}{l}\text { Grade } 2 \text { reduced renal function at cycle I. Cohort was expanded with } \\
\text { three more patients. }\end{array}$ & PD \\
\hline & 113 & Lung (IV) & 2 & 0 & & SD \\
\hline & 114 & Pancreas (IV) & 2 & I & Grade 3 fatigue at cycle I (DLT). & SD \\
\hline & 215 & Colon (IV) & 2 & 0 & & PD \\
\hline \multirow[t]{3}{*}{120} & 216 & Melanoma (IV) & 2 & 0 & Grade 2 reduced renal function at cycle 1. & PD \\
\hline & 117 & Melanoma (IV) & 4 & 0 & $\begin{array}{l}\text { Grade } 2 \text { reduced renal function at cycle I. Hypersensitivity reaction } \\
\text { at cycle } 4 \text { (SAE) (Pt-naïve). }\end{array}$ & SD \\
\hline & 218 & Renal cell (IV) & 3 & 0 & Hypersensitivity reaction at cycle 3 (SAE) (Pt-naïve). & SD \\
\hline
\end{tabular}

Abbreviations: $\mathrm{DLT}=$ dose-limiting toxicity; $\mathrm{GIST}=$ gastrointestinal stromal tumour; $\mathrm{PD}=$ progressive disease; $\mathrm{Pt}=$ platinum; $\mathrm{NE}=$ not estimated; $\mathrm{SAE}=$ serious adverse event; $\mathrm{SD}=$ stable disease.

Table 4 Summary of all related adverse events

\begin{tabular}{|c|c|c|c|c|c|c|c|}
\hline \multirow[b]{3}{*}{$n$} & \multicolumn{7}{|c|}{ NC-6004 dose level (in $\mathrm{mg} \mathrm{m}^{-2}$ ) } \\
\hline & 10 & 20 & 40 & 60 & 90 & 120 & Total \\
\hline & 1 & 1 & 3 & 3 & 6 & 3 & 17 \\
\hline \multicolumn{8}{|l|}{ Haematological toxicity } \\
\hline \multicolumn{8}{|c|}{ Blood and lymphatic system disorders } \\
\hline Thrombocytopenia & । & 0 & 0 & 0 & I & 0 & 2 \\
\hline Constipation & 0 & 0 & 0 & 0 & 0 & I & I \\
\hline Dry mouth & 0 & 0 & 0 & । & 0 & 0 & । \\
\hline Nausea & 0 & | & । & i & 4 & । & 8 \\
\hline Paraesthesia oral & 0 & 0 & 0 & 0 & 0 & 1 & । \\
\hline Tongue ulceration & 0 & 0 & 0 & 0 & 1 & 0 & I \\
\hline Vomiting & 0 & 0 & । & । & 4 & । & 7 \\
\hline Hypersensitivity & I & 0 & 0 & 2 & I & 2 & 6 \\
\hline \multicolumn{8}{|l|}{ Metabolism and nutrition disorders } \\
\hline Anorexia & 0 & 0 & 2 & I & 4 & I & 8 \\
\hline Decreased appetite & 0 & 0 & 0 & । & 0 & 0 & । \\
\hline Dehydration & 0 & 0 & 0 & 0 & I & 0 & i \\
\hline Hypomagnesemia & 0 & 0 & 0 & 0 & I & 0 & I \\
\hline \multicolumn{8}{|l|}{ Nervous system disorder } \\
\hline Dizziness & 0 & 0 & 0 & 0 & 0 & 1 & 1 \\
\hline Neuropathy peripheral & । & 0 & 0 & । & 0 & 0 & 2 \\
\hline Peripheral sensory neuropathy & 0 & 0 & 0 & 0 & I & 0 & i \\
\hline \multicolumn{8}{|l|}{ Renal and urinary disorder } \\
\hline Renal impairment & 0 & 0 & 2 & 0 & 2 & 2 & 6 \\
\hline \multicolumn{8}{|c|}{ Skin and subcutaneous tissue disorder } \\
\hline Alopecia & 0 & 0 & 0 & 0 & 0 & । & । \\
\hline
\end{tabular}


Table 5 Pharmacokinetic parameters per cohort for total, micellar, and ultrafiltrable Pt of NC-6004 (mean \pm s.d.)

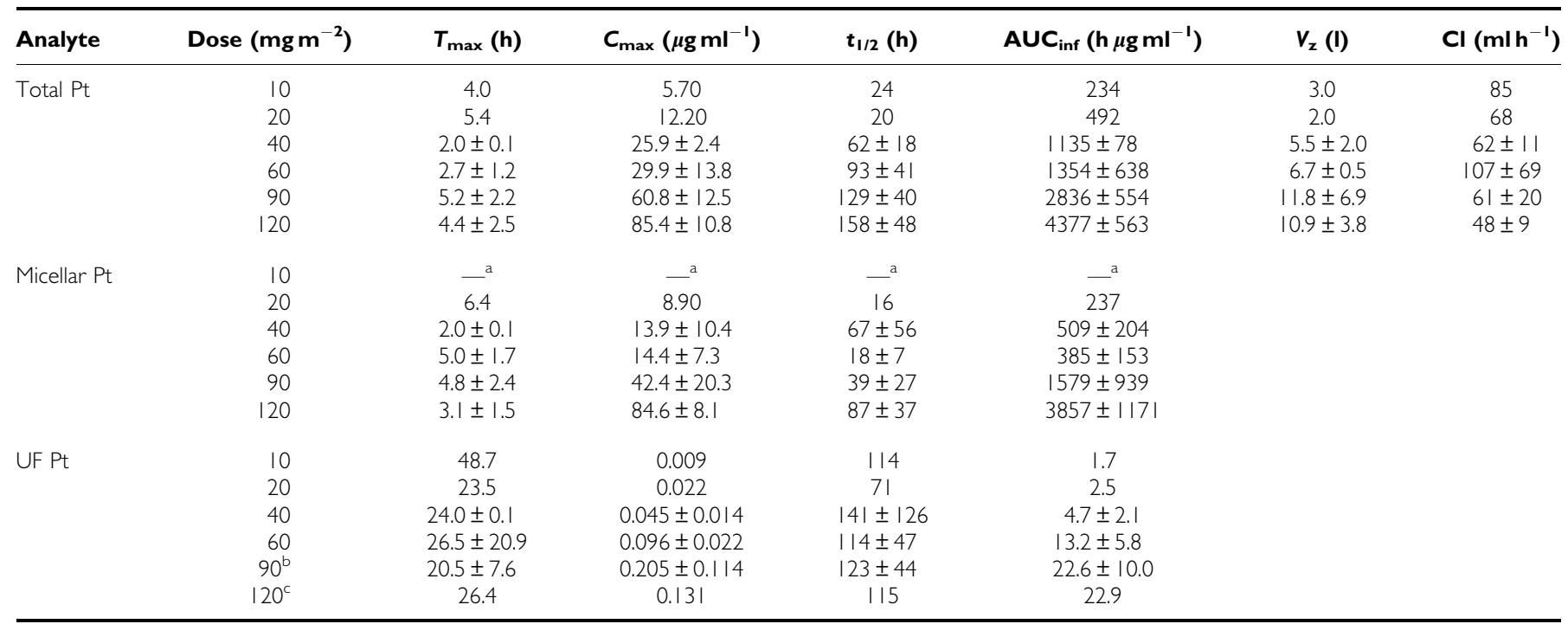

Abbreviations: $\mathrm{AUC}_{\mathrm{inf}}=$ area under concentration-time curve from zero to infinity; $\mathrm{Cmax}=$ maximum concentration; $\mathrm{Cl}=\mathrm{clearance}$; $\mathrm{Pt}=\mathrm{platinum}$; $\mathrm{QC}=\mathrm{quality}$ control; $T_{\max }=$ time to maximum concentration; UF Pt = ultrafilterable platinum; Vz= volume of distribution. ${ }^{a}$ Data not valid - QCs out with acceptance limit. ${ }^{\mathrm{b}} \mathrm{I}$ data was not valid QCs out with acceptance limit. '2 data were not valid - QCs out with acceptance limit.

\section{Pharmacokinetics}

Pharmacokinetic parameters for Pt measured per cohort in the three different matrices are shown in Table 5. A typical plasma concentration-time profile is also shown in Figure 3.

Pharmacokinetics of total plasma Pt was characterised by longer $t_{1 / 2}$, and higher $C_{\max }$ and $\mathrm{AUC}_{\text {inf }}$ with smaller $V_{\mathrm{z}}$ and $\mathrm{Cl}$ compared with those of cisplatin, indicating that the blood circulation of cisplatin was prolonged by the incorporation into the micelles. Thus, the $C_{\max }$ and $\mathrm{AUC}_{\mathrm{inf}}$ of NC-6004 at $120 \mathrm{mg} \mathrm{m}^{-2}$ were approximately 11-fold higher than those of cisplatin at an equivalent dose (Kitajima et al, 1987). The $t_{1 / 2}$ of NC-6004 at $120 \mathrm{mg} \mathrm{m}^{-2}$ was longer than that of cisplatin at an equivalent dose, $14.6 \mathrm{~min}$ for the initial phase and $73.8 \mathrm{~h}$ for the terminal phase (Kitajima et al, 1987). The $V_{\mathrm{z}}$ and $\mathrm{Cl}$ of NC-6004 were smaller than those of cisplatin, 521 and $350 \mathrm{mlh}^{-1}$, respectively (Calvert et al, 1993). The AUC ${ }_{\text {inf }}$ and $C_{\max }$ of NC-6004 increased in a dose-dependent manner, and there was no apparent change in $\mathrm{Cl}$ with increasing dose.

For the gel-filterable Pt (intact micellar formulation), the $T_{\max }$ was similar to that of total plasma $\mathrm{Pt}$, the $t_{1 / 2}$ generally mirrored that of total plasma $\mathrm{Pt}$, and the $C_{\max }$ and $\mathrm{AUC}_{\text {inf }}$ values were approximately $88 \%$ of those of total plasma Pt.

For the ultrafilterable Pt (active species including cisplatin), the $C_{\max }$ at $120 \mathrm{mg} \mathrm{m}^{-2}$ was 34 -fold lower than that of non-protein-bound cisplatin after the administration of an equivalent dose of cisplatin (Kitajima et al, 1987), which might be responsible for the lower incidence of toxicity compared with that associated with cisplatin therapy. Conversely, $t_{1 / 2}$ and $\mathrm{AUC}_{\text {inf }}$ at $120 \mathrm{mg} \mathrm{m}^{-2}$ of NC-6004 were 230 -fold and 8.5-fold larger, respectively, than those of non-proteinbound cisplatin after the administration of an equivalent dose of cisplatin (Kitajima et al, 1987). The persistence of active Pt species might indicate an improved efficacy of NC-6004. Furthermore, $T_{\max }(24 \mathrm{~h}$ or greater) was delayed compared with that of total plasma Pt or gelfilterable Pt, suggesting that NC-6004 provides a delayed and sustained release of potentially active Pt species after the administration period.

\section{DISCUSSION}

NC-6004 was well tolerated with minimal nephrotoxicity and no significant myelosuppression, ototoxicity, emesis, or neurotoxicity, but a higher rate of hypersensitivity reactions than predicted. No DLT per protocol was seen at doses up to $90 \mathrm{mg} \mathrm{m}^{-2}$ where 1 DLT

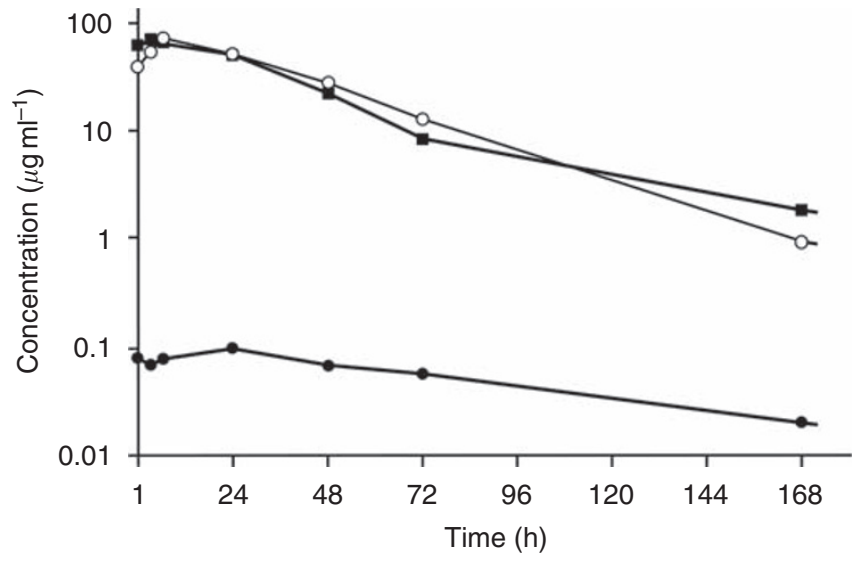

Figure 3 Plasma Pt concentration-time curve from a patient treated at $90 \mathrm{mg} \mathrm{m}^{-2}$ of NC-6004. $\mathbf{a}$, total Pt, $\bigcirc$, gel-filterable Pt, - ultrafilterable Pt.

(grade 3 fatigue) was experienced by one out of six patients, and no further DLT per protocol was seen at $120 \mathrm{mg} \mathrm{m}^{-2}$ when the study was discontinued. In general, the toxicities of NC-6004 were less severe and less frequent compared with cisplatin, particularly nausea/vomiting, anorexia, alopecia, and haematological toxicity.

In this study, dose delays/reductions were mainly due to effects on renal function. Despite the introduction of 1 to 1.51 of fluid over $2 \mathrm{~h}$, following NC-6004 administration, rising creatinine and/ or reduction in estimated creatinine $\mathrm{Cl}$ or ${ }^{51} \mathrm{Cr}$-EDTA $\mathrm{Cl}$ affected two out of six patients at $90 \mathrm{mg} \mathrm{m}^{-2}$ and two out of three patients at $120 \mathrm{mg} \mathrm{m}^{-2}$, although the creatinine level returned to baseline in 2 weeks. Cisplatin therapy requires a total $8 \mathrm{~h}$ hydration, comprising 1-2l over $4 \mathrm{~h}$ of hydration, both before and after the administration of cisplatin, to prevent nephrotoxicity. Another potential advantage of NC-6004 over cisplatin is, therefore, the reduced need for hydration, and that renal impairment was kept to minimum by modest hydration. Whether hydration is absolutely necessary for NC-6004 therapy to reduce the incidence of renal impairment remains to be assessed in a future trial.

Dose interruptions due to toxicity in this study were all related to hypersensitivity reactions, which occurred unpredictably at four 
out of six dose levels $\left(10,60,90\right.$, and $\left.120 \mathrm{mg} \mathrm{m}^{-2}\right)$ in six patients. The first three patients had previous Pt therapy and the last three patients were Pt-naïve, thus, the occurrence of hypersensitivity reaction depends on neither dose level nor the previous $\mathrm{Pt}$ exposure. The use of a prophylactic regimen of dexamethasone, ranitidine, and chlorphenamine, previously described, was not sufficient to prevent hypersensitivity reactions in two patients at $120 \mathrm{mg} \mathrm{m}^{-2}$, therefore a more stringent prophylactic regimen (Kwon et al, 2002) might be necessary. As most of the patients recruited in this Phase I study progressed by the end of cycle 2, and hypersensitivity reactions developed after a minimum of two cycles of NC-6004, despite the pre-medication, it was considered that this phase I study was not the appropriate setting to assess alternative pre-medication strategies. Therefore, the study was discontinued, so that this problem could be assessed in a future trial. In preclinical studies, the antigenicity of NC-6004 was examined compared with cisplatin, polymer vehicle, polymer-bound cisplatin (not in a micelle form), and cisplatin - plasma protein complex. The results indicated that cisplatin and polymer vehicle are not antigenic, and the highest extent of antigenicity observed was in cisplatin-plasma protein complex, followed by NC-6004 and then polymer-bound cisplatin (not in a micelle form). This suggests that the hypersensitivity reaction to NC-6004 may have been due to plasma protein-bound cisplatin, which is formed by rapid binding of plasma protein to released cisplatin, which then circulates in the blood for a prolonged period. However, the mechanism has not yet been fully clarified.

Taking account of the incidence of hypersensitivity reaction and renal impairment, $120 \mathrm{mg} \mathrm{m}^{-2}$ was considered to be close to the MTD, such that $90 \mathrm{mg} \mathrm{m}^{-2}$ was most likely the RD for monotherapy for future studies, although the definition per protocol of the MTD was not actually reached.

In spite of the patients generally being heavily pretreated, some evidence of disease stabilisation was seen, and seven patients demonstrated SD after 6 weeks of treatment. Efficacy will be further assessed in a future trial.

\section{REFERENCES}

Calvert H, Judson I, Van der Vijgh WJF (1993) Platinum complexes in cancer medicine: pharmacokinetics and pharmacodynamics in relation to toxicity and therapeutic activity. Pharmacokinet Cancer Chemother 17: $189-217$

Hartmann JT, Lipp H-P (2003) Toxicity of platinum compounds. Expert Opin Pharmacother 4: 889-901

Judson I, Kelland LR (2000) New developments and approaches in the platinum arena. Drugs 59(Suppl. 4): 29-36

Kartalou M, Essigmann JM (2001) Mechanisms of resistance to cisplatin. Mutat Res 478: 23-43

Kelland LR, Sharp SY (1999) Platinum compounds in cancer therapy. Curr Opin Oncol Endocrine Metabolic Invest Drugs 1: 380-385

Kitajima K, Fukuoka M, Kobayashi S, Kusunoki Y, Takada M, Negoro S, Matsui K, Sakai N, Ryu S, Takifuji N (1987) Studies on appropriate administration of cisplatin based on pharmacokinetics and toxicity. Jpn J Cancer Chemother 14: 2517-2523

Kwon JS, Elit L, Finn M, Hirte H, Mazurka J, Moens F, Trim K (2002) A comparison of two prophylactic regimens for hypersensitivity reactions to paclitaxel. Gynecol Oncol 84: 420-425

Maeda $H$ (2001) The enhanced permeability and retention (EPR) effect in tumor vasculature: the key role of tumor-selective macromolecular drug targeting. Advan Enzyme Regul 41: 189-207

Maeda H, Matsumura Y (1989) Tumoritropic and lymphotropic principles of macromolecular drugs. Crit Rev Ther Drug Carrier Syst 6: $193-210$

Maeda H, Wu J, Sawa T, Matsumura Y, Hori K (2000) Tumor vascular permeability and the EPR effect in macromolecular therapeutics: a review. J Control Rel 65: 271-284

Matsumura Y, Maeda H (1986) A new concept for macromolecular therapeutics in cancer chemotherapy: mechanism of tumoritropic
The pharmacokinetic analysis indicated the prolonged circulation of NC-6004 in the blood, and delayed and sustained release of potentially active Pt species after the administration of NC-6004. More importantly, the observed lower $C_{\max }$ for ultrafilterable $\mathrm{Pt}$ compared with that of non-protein-bound cisplatin, after the cisplatin injection, might result in the reduction of cisplatinrelated toxicity. Furthermore, the higher $\mathrm{AUC}_{\text {inf }}$ and $t_{1 / 2}$ for ultrafilterable Pt compared with that of non-protein-bound cisplatin after the cisplatin injection might enhance the efficacy of NC-6004. However, an increase in the AUC of plasma protein-bound cisplatin because of rapid binding of plasma protein to released cisplatin might result in a higher risk of hypersensitivity reaction.

In conclusion, this Phase I study has confirmed that NC-6004 exhibits pharmacokinetic characteristics completely different from those of cisplatin, resulting in the reduction of cisplatin-related toxicity and the improvement of patient's quality of life so that the patients can take therapy without hospitalisation for hydration and treatment of cisplatin-related toxicities. The data obtained from this study are believed to open new avenues for the use of this micellar formulation in the clinic. The assessment of the most appropriate prophylactic regimen for hypersensitivity reactions, whether hydration is necessary and of efficacy are now underway in ongoing NC-6004 studies.

\section{ACKNOWLEDGEMENTS}

This work was supported in part by the National Institute of Biomedical Innovation (Tokyo, Japan). Staff working on this project at the two UK academic institutions are supported through the Experimental Cancer Medicine Centre initiative. The Newcastle Experimental Cancer Medicine Centre is supported by a programme grant from Cancer Research UK and the department of Health. The Belfast Experimental Cancer Medicine Centre is supported by a programme grant from Cancer Research UK and the Northern Ireland Health and Social Care Research and Development Division. accumulation of proteins and the antitumor agent smancs. Cancer Res 46: $6387-6392$

Nishiyama N, Kataoka K (2001a) Preparation and characterization of sizecontrolled polymeric micelle containing cis-dichlorodiammineplatinum (II) in the core. J Control Rel 74: 83-94

Nishiyama N, Kato Y, Sugiyama Y, Kataoka K (2001b) Cisplatin-loaded polymer-metal complex micelle with time-modulated decaying property as a novel drug delivery system. Pharm Res 18: 1035-1041

Nishiyama N, Okazaki S, Cabral H, Miyamoto M, Kato Y, Sugiyama Y, Nishio K, Matsumura Y, Kataoka K (2003) Novel cisplatin-incorporated polymeric micelles can eradicate solid tumors in mice. Cancer Res 63: $8977-8983$

Nishiyama N, Yokoyama M, Aoyagi T, Okano T, Sakurai Y, Kataoka K (1999) Preparation and characterization of self-assembled polymermetal complex micelle from cis-dichlorodiammineplatinum (II) and poly(ethylene glycol)-poly( $\alpha, \beta$-aspartic acid) block copolymer in an aqueous medium. Langmuir 15: 377-383

Pinzani V, Bressolle F, Hang IJ, Galtier M, Balyac JP, Balmes P (1994) Cisplatin-induced renal toxicity and toxicity-modulating strategies: a review. Cancer Chemother Pharmacol 35: 1-9

Sharp SY, O'Neill CF, Rogers P, Boxall FE, Kelland LR (2002) Retention of activity by the new generation platinum agent AMD0473 in four human tumour cell lines possessing acquired resistance to oxaliplatin. Eur $J$ Cancer 38: 2309-2315

Uchino H, Matsumura Y, Negishi T, Koizumi F, Hayashi T, Honda T, Nishiyama N, Kataoka K, Naito S, Kakizoe T (2005) Cisplatinincorporating polymeric micelles (NC-6004) can reduce nephrotoxicity and neurotoxicity of cisplatin in rats. Br J Cancer 93: 678-687

Yokoyama M, Okano T, Sakurai Y, Suwa S, Kataoka K (1996) Introduction of cisplatin into polymeric micelle. J Control Rel 39: 351-356 